\title{
Application of Krueger's Model in Explaining Entrepreneurial Intentions among Employees in Morocco
}

\author{
Taoufik Yatribi \\ Department of Management \& Audit \\ The National School of Management, Tangier, Morocco \\ Email: t.yatribi@gmail.com \\ Phone \#: +212 649378671
}

Received: February 01, 2016 Accepted: February 15, 2016 Published: April 04, 2016

doi:10.5296/ijhrs.v6i2.9259 URL: http://dx.doi.org/10.5296/ijhrs.v6i2.9259

\begin{abstract}
Today, the entrepreneurship became an orientation of career among several employees. In spite of this attraction towards entrepreneurship, the study of the entrepreneurial intention is necessary to understand why certain employees decide to leave their employment to create their company. This research thus suggests explaining the entrepreneurial intention among the employees, specifically among the executives-engineers.

The method used rests on the technique of the structural equations of a theoretical model widely accepted in the literature, namely Krueger's model. The test leans on the statistical treatment of 376 questionnaires administered by electronic way.

The results of the statistical analyses allow validating globally Krueger's model, we find that the perceived desirability and feasibility influences the entrepreneurial intention. Then, if the experience has an effect on the perceived feasibility, it has not impact on the perceived desirability. We conclude that the used theoretical model remains insufficient to explain the entrepreneurial intention in an organizational context. Our study allows highlighting the necessity of using other complementary theoretical approaches to explain and predict better the entrepreneurial intention among the employees. The theoretical and managerial implications of this research will be presented, and avenues of research will be proposed.
\end{abstract}

Keywords: Entrepreneurial intention, Krueger's model, employees (executives-engineers) 


\section{Introduction}

In a context where the individuals are at the request of more freedom, more dignity and more inhalation in the personal development, the entrepreneurship seems as a way of career quite credible allowing the employees to extend their career beyond the borders of the company. The entrepreneurship is become in fact a new form of career development in a context of crisis where the threats on the employment can bring certain young adults to envisage a radical change of activity (Simosi, Rousseau \& Daskalaki, 2015).

The entrepreneurial behavior is an act which is born within a process under construction. The intention establishes the starting point of this process leading the individual to create his company (Bird, 1988). The intention is thus situated upstream to this process. According toKrueger \& Kickul (2011), The theoretical models explaining the entrepreneurial intention gives important opportunities to clarify better the entrepreneurial field and increase the know-how of the researchers at the level of the entrepreneurial behavior and have the excellent predictive validity. However, the most researches on the entrepreneurial intention are focused on the population of the students. Very few researches studied the entrepreneurial intention among the employees. This researchcomes to contribute to fill this gap, she suggests to explain the entrepreneurial intention among the employees.

Our article is divided into four parts. After presenting the theoretical framework and hypothesis of our study, we will tackle the method chosen for this research. The third part will be dedicated to results. We will then discuss the major characteristics of this research. After that, several recommendations will be drawn up and research leads will be determined.

\section{Theoretical Framework and Hypotheses}

To explain the entrepreneurial intention, the literature proposes us several theoretical frame (for example, Ajzen \& Fishbein (1970); Learned (1992);Krueger (1993);Boyd \& Vozikis (1994) ;Davidsson (1995)) to explain and predict the intention. In our case, we chose the theoretical frame proposed byKrueger (1993). This choice is rested by recent meta-analysis ofSchlaegel \& Koenig (2014), Who show that the perceived desirability and feasability are the best prédicteurs of the entrepreneurial intention. These two variables are two main components of the entrepreneurial intention in the model of Krueger (1993). It's also necessary to note that Norris Krueger is today, the most referenced author in the entrepreneurship field.

In his article published in 1993 in «Entrepreneurship Theory and practice », Krueger (1993)proposes a model which integrates at the same time the Shapero's model (Shapero \& Sokol, 1982) and Ajzen's model (Ajzen, 1991). He integrated the concept of the intention into the model of the entrepreneurial event from Shapero. Indeed,Krueger (1993)demonstrated that attitudes and subjective norms in the model of the theory of the planned behavior (TPB) is conceptually bound to the perceived desirability of the model of the entrepreneurial event (Shapero \& Sokol, 1982), whereas the perceived behavioral control in the TPB corresponds to the perceived feasibility in the model of the entrepreneurial event (Shapero \& Sokol, 1982). 


\section{Macrothink}

The author resumes the fact that the creation of a company is a strategic behavior, which can be predicted more exactly by the intention with regard to the behavior than directly by the faiths of the individual, the attitudes or the personality. According to Krueger (1993), the intention depends to the perceived desirability and feasibility, and the propensity to act, knowing that the aforementioned propensity plays only a moderating role.

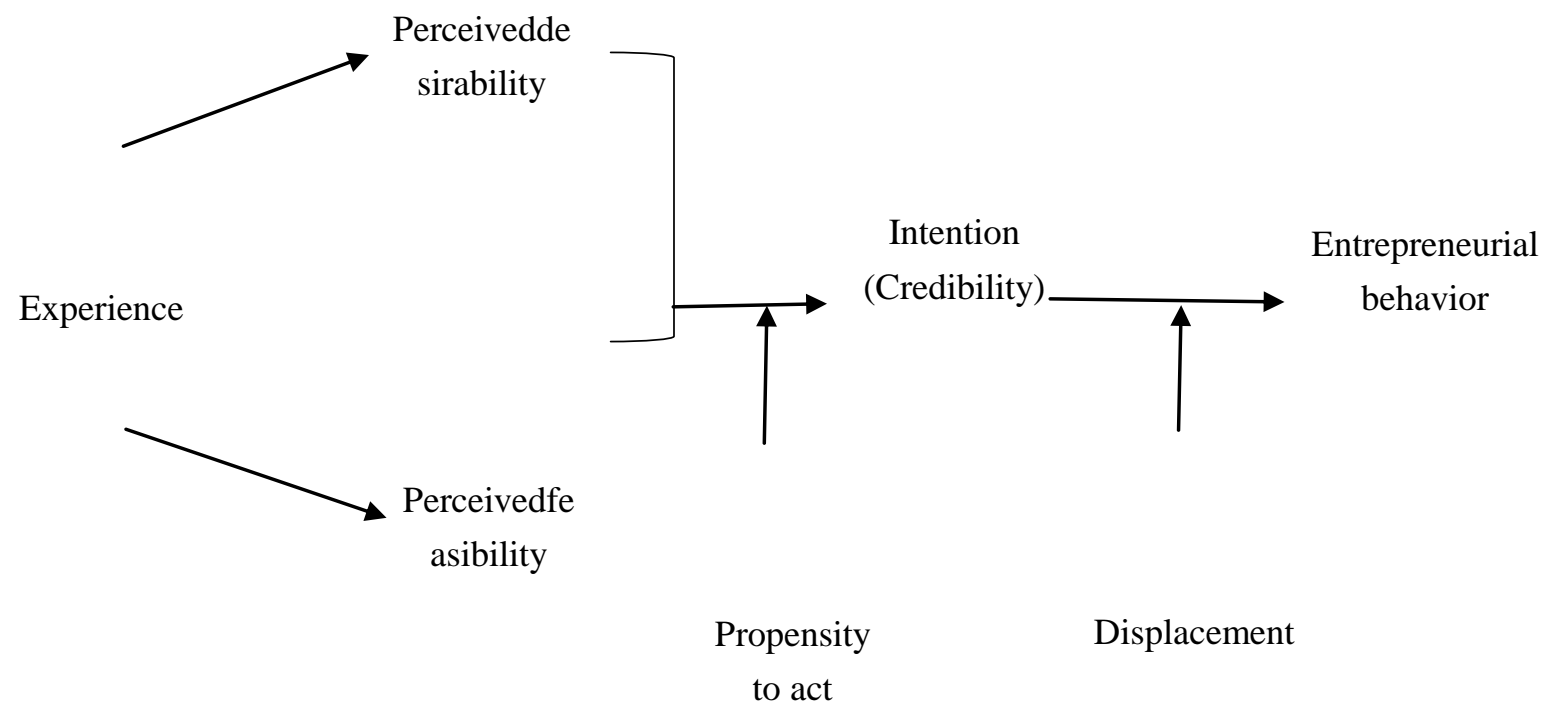

Figure 1. Krueger's model (1993)

Source : Krueger (1993)

Perceived desirability is defined as the degree of attraction which an individual perceives a given behavior. The perceived feasibility is defined as the perception of the ease or the difficulty towards the behavior. If we make an exception of the moderating variable, that is the proportion to act, only both components, the perceived desirability and feasibility explain only to them the entrepreneurial intention.

For that an individual changes career orientation in his life, such as the decision to start his own company, an event has to come to break the routine. However, as specify it(Krueger \& Brazeal, 1994), the individual seizes the opportunity to create a company, if he expresses an initial trend, a favorable attitude towards the new business start-up. This way, the author bases his reflection on the concept of "credibility" of the action, which, he makes a reference to the entrepreneurial intentions : "In Shapero's SEE model entrepreneurial intentions require that founders perceive entrepreneurship as a credible $\gg($ Krueger \& Carsrud (1993)-Quoted by Kolvereid (1996)). Indeed, «Starting a new venture must be a believable opportunity »(Krueger, 1993). If the creator perceives the action as credible, it will be incited to dash in entrepreneurship.

It should be noted that the first entrepreneurial experiences act indirectly through an adjustment of the perceptions of the desirability and the feasibility, to influence the intention and the action. If each of the first two elements (perceived desirability and feasibility) are resumed in the same prospect as that developed byShapero \& Sokol (1982), Krueger details more that the role of the propensity to act and his joint with these two concepts. The 
propensity to act reflects the psychological component of the intentions. It is an arrangement to act who translates the evolutionary character of the intention, as far as she answers the interrogation "will I actually do it ?".

ForShapero \& Sokol (1982), is especially the desire to control the environment (desire of independence and the interiorization of locus of the control). For others (in particular the current of the personality traits), the propensity to act corresponds to personality traits which return to the notion of the internal locus of control. The place of locus of control made a reference to the faiths of the individuals as for their control of the events. Generally, the entrepreneurs have an internal locus of control, which incites them to pass to action compared of the individuals having a external locus of control.

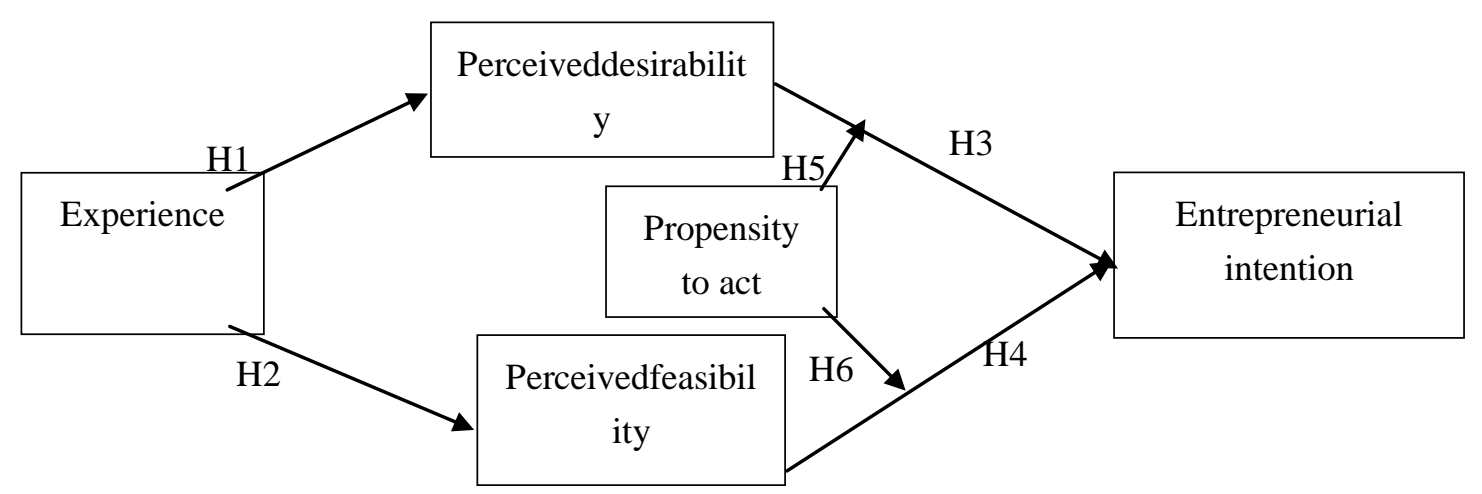

Figure 2. Conceptual framework

We keep the same structure of the model of Krueger (1993), to test him on a population of employees, we put forward the following hypotheses which translate the links between the variables of the model :

H1. The experience has a positive effect on the perceived desirability.

H2. The experience has a positive effect on the perceived feasibility.

H3. The perceived desirability has a positive effect on theentrepreneuriale intention.

H4. The perceived feasibility has a positive effect on the entrepreneuriale intention.

H5. The propensity to act moderates the relationship between perceived desirability and entrepreneurial intention (i.e. the relationship between perceived desirability and entrepreneurial intention is stronger when thepropensity to act is high).

H6.The propensity to act moderates the relationship between perceived feasibilityand entrepreneurial intention (i.e. the relationship between perceived feasibilityand entrepreneurial intention is stronger when thePropensity to act is high). 


\section{$\Lambda$ Macrothink}

\section{Methods}

\subsection{Data source}

We collected our data in Morocco. The study population is the executives-engineers. This choice is justified by the fact that this population turns out strategic for organizations. The engineers are indeed a major source of innovation (Boyer \& Michel, 1998), and of accumulation of skills for the company and the country (Lavoie \& Finnie, 1998). Fayolle(2001) quotesGaudin(1984)to remind) that "their scientific and technical training as well as their work experience confer them a capacity to be innovated and prepare them, in particular, to be elements pivots of the technological innovation".

For practical reasons, it is hard to survey the Moroccan engineers' population in its totality. Thus, we chose a convenience sample. Since then, we resorted to directories of former graduates of several engineering schools. In order to avoid a bias related to the convenience sample, we tried to study individuals that operate in different fields. We have conducted a sampling on the basis of a rational choice. This technique, which turned out to be particularly suitable to the data we have gathered, enables us to choose precisely the elements of a sample engineer population whose characteristics are well known to us (Thietart, 2014).

Furthermore, the questionnaire was applied on 5000 engineers by electronic means. If 376 useable answers have been received, it is difficult to calculate a response rate since many respondents did not received the questionnaire because they do not check their email boxes anymore.

Our sampling is made of $64,6 \%$ men and $35,4 \%$ women . $68 \%$ of the respondents work in the private sector against $32 \%$ the public sector. Concerning the work field, we have recorded $25 \%$ computer engineers, $11,15 \%$ industrial engineers, $8,11 \%$ agronomists, $6,42 \%$ mechanical engineers, $4,39 \%$ public works engineers, 3,72\% electrical engineers and 2,36\% electronic engineers.

\subsection{Measures}

All the constructs used a 7-point Likert scale response that ranged from strongly disagree (1) to strongly agree (7).

Entrepreneurial intention : According to the proposed measure by Thompson (2009), the intention was measured by six items : (1) Never search for business start-up opportunities ${ }^{\circledR}$ (2) Are saving money to start a business (3) Don't read books on how to set up a firm ${ }^{\circledR}$ Have no plans to launch your own business ${ }^{\circledR}(5)$ Spend time learning about starting a firm (6) Have you Intend to set up a company in the future?

Perceived desirability:For more clarity in the Moroccan context, we shall call him in our study "attraction for the entrepreneurship". The attraction was measured by means of a single item: the idea to create your company seems to you, on a scale going of "not at all attractive" to "completely attractive" (see,Krueger, Reilly \& Carsrud (2000)).

Perceived feasibility :We prefer to hold the term of "perceived capacity" rather than that of 


\section{Macrothink}

"perceived behavioral control", because of the biggest clarity of the concept in the Moroccan context. Thus the received entrepreneurial capacity makes reference to the degree with which a engineer thinks of be able to create a company.

Perceived capacity were measured with 4-item scale from Yatribi\&Balhadj (2016b) : (1) You feel capable of bringing to successful a project of new business start-up (2) You think of mastering personally the process of creation of a company (3) It seems to you possible to take up a project of creation and assure his success (4) You trust in your ability to succeed to start a business.

Propensity to act: Propensity to act were measured with 4-item scale. (1) It's useless to make forecasts on the future, because everything is a question of luck (2) You often think that what should arrive will arrive no matter are your acts ". (3) The success is a question of luck (4) You think that the life is a poker game.

\section{Results}

To test the model of research (Fig. 2) and the hypotheses (H1, H2, H3, H4, H5 and H6), we are going to use the technique of the structural equations. The function of adjustment of the maximum Likelihood (ML), most usually used, is used. We respected the approach in two stages recommended by Thietart (2014). At first, the measuring instruments of the constructed were estimated. Their reliabilities and their validities (i.e. convergent validity and discriminant validity) were verified. Secondly, the relations were, in their turn, tested

\subsection{Evaluation of the Model of Measure}

At first, we made aconfirmatory analyzes so that we can estimate the measure model. The measure model quality (RMSEA, AGFI, RFI, TLI and CFI) as well as the parameters considered standardized by items, extracted average variances and reliability of the constructed are presented in the table 1 . 


\section{Ml Macrothink}

International Journal of Human Resource Studies

ISSN 2162-3058

2016, Vol. 6, No. 2

Table1.Results of the measure models with Maximum Likelihood (ML)

\begin{tabular}{|c|c|c|c|c|c|}
\hline & & $\begin{array}{l}\text { Entrepreneurial } \\
\text { intention }\end{array}$ & $\begin{array}{l}\text { Perceived } \\
\text { desirability }\end{array}$ & $\begin{array}{l}\text { Perceived } \\
\text { feasibility }\end{array}$ & $\begin{array}{l}\text { Propensity } \\
\text { to act }\end{array}$ \\
\hline \multirow[t]{5}{*}{ Goodness-of-fit } & RMSEA $(<0,08)$ & 0,071 & 0,065 & 0,037 & 0,055 \\
\hline & AGFI $(>0,90)$ & 0,954 & 0,974 & 0,977 & 0,903 \\
\hline & RFI $(>0,95)$ & 0,953 & 0,988 & 0,942 & 0,961 \\
\hline & TLI $(>0,90)$ & 0,922 & 0,917 & 0,989 & 0,972 \\
\hline & CFI $(>0,90)$ & 0,928 & 0,944 & 0,906 & 0,988 \\
\hline \multirow{8}{*}{$\begin{array}{l}\text { Convergent } \\
\text { validity }\end{array}$} & Standardizedfactorialweight $(>0,5)$ & & & & \\
\hline & Item 1 & $0,890(0,042)$ & 1 & $\begin{array}{l}0,861 \\
(0,028)\end{array}$ & $\begin{array}{l}0,889 \\
(0,027)\end{array}$ \\
\hline & Item 2 & $0,791(0,034)$ & & $\begin{array}{l}0,890 \\
(0,035)\end{array}$ & $\begin{array}{l}0,901 \\
(0,020)\end{array}$ \\
\hline & Item 3 & $0,591(0,050)$ & & $\begin{array}{l}0,910 \\
(0,027)\end{array}$ & $\begin{array}{l}0,879 \\
(0,013)\end{array}$ \\
\hline & Item 4 & $0,782(0,029)$ & & $\begin{array}{l}0,790 \\
(0,015)\end{array}$ & $\begin{array}{l}0,977 \\
(0,011)\end{array}$ \\
\hline & Item 5 & $0,922(0,041)$ & & & \\
\hline & Item 6 & $0,682(0,030)$ & & & \\
\hline & $\begin{array}{l}\text { Extractedaverage } \quad \text { variance } \\
(\rho \mathrm{vc}>0,5)\end{array}$ & 0,61 & 0,81 & 0,77 & 0,83 \\
\hline $\begin{array}{l}\text { Discriminant } \\
\text { validity }\end{array}$ & \multicolumn{5}{|c|}{$\begin{array}{l}\text { The discriminant validity tested as indicated in the methodological part is systematically } \\
\text { correct. }\end{array}$} \\
\hline Fiability & p Jöreskog $(>0,70)$ & 0.90 & 0.87 & 0.79 & 0.89 \\
\hline
\end{tabular}

Note :Numbers in parentheses refer to Standard-Deviations (SD). Globally, when the loading is twice upper at least to the standard deviation, the test "t" is significant (> 2).

The results of the modelling show that the $\rho$ Jöreskog's coefficients of internal coherence are raised $(>0,70)$ what means that each of the items is better explained by the constructed to which he relates that by the fate. In other words, the scales of measure of the histories of the intention, the structures between variables of measure and built appear to be in adequacy with the collected data. Indicators are thus reliable.

Two forms of convergent validity were studied. The low shape (tests " $t$ " > 2) consists in verifying that the weights of the relations (between the measures and builds them) are statistically different 0(Bagozzi \& Yi, 1991). The strong shape rests on the examination of the variance shared between a constructed and its measures. This extracted average variance ( $\rho v c)$ must be superior to 0,50(Fornell \& Larcker, 1981).

These two criteria are satisfied in our case, the results are thus satisfactory. The discriminating validity supposes that the variance shared between the constructed is lower than the variance shared between the constructed and their measures(Fornell \& Larcker, 


\section{Macrothink}

1981). The analysis recommended byBagozzi \& Yi (1991)rest on the comparison between the values of $\chi 2$ of a free leaving model the correlations between various built and a model where the correlations between built are fixed to 1 . If the difference is significant with regard to the difference of degree of freedom, we can conclude that the tested model is better than the model forces and if the constructed are different. In our case, all the indicators show satisfactory results the various criteria both in terms of adjustment and of reliability and validity of line, the statistical analysis can be pursued.

\subsection{Evaluation of the causal models}

The results of the modelling reveal that the tested model is specified well. Indeed, we held five indicators most usually used to estimate our model. All the indicators are satisfactory or close to recommended standards (table 2). As a consequence, the model is acceptable.

Tableau 2.Result of the structural model with ML

\begin{tabular}{|l|l|}
\hline Indicators & Goodness-of-fit \\
\hline RMSEA $(<0,08)$ & 0.07 \\
\hline AGFI $(>0,90)$ & 0.91 \\
\hline RFI $(>0,95)$ & 0.93 \\
\hline TLI $(>0,90)$ & 0,91 \\
\hline CFI $(>0,90)$ & 0,94 \\
\hline
\end{tabular}

Tableau 3.Results of the regression with ML $(\mathrm{N}=376)$

\begin{tabular}{|l|l|l|}
\hline Relations model & Estimate & $\mathrm{P}$ \\
\hline Perceiveddesirability $<--$ Experience &,- 045 &, 385 \\
Perceivedfeasibility $\quad$--- Experience &, 148 &, 004 \\
Entrepreneurial intention <--- Perceiveddesirability &, 428 & $* * *$ \\
Entrepreneurial intention <--- Perceivedfeasibility &, 317 & $* * *$ \\
Entrepreneurial intention <--- Propensity to act &, 033 &, 394 \\
\hline
\end{tabular}




\begin{tabular}{|l|l|l|}
\hline Relations model & Estimate & $\mathrm{P}$ \\
\hline Entrepreneurial intention <--- Propensity to act x Perceived desirability &, 107 &, 002 \\
Entrepreneurial intention <--- Propensity to act x Perceived feasibility &,- 042 &, 219 \\
\hline
\end{tabular}

Note : ${ }^{*} \mathrm{p}<0,05, * * \mathrm{p}<0,01, * * * \mathrm{p}<0,001$

We have noticed that experience hasn't a significant impact on the perceived desirability ( $\beta=$ $-0,045, \mathrm{p}>0.05)$, our hypothesis $\mathrm{H} 1$ is invalidated. On the other hand, the experience has a significant effect on the perceived feasibility $(\beta=0,148, \mathrm{p}<0,01)$, the hypothesis $\mathrm{H} 2$ is validated. We can also see that the perceived desirability and the perceived feasibilityhave a positive and significant effect on the entrepreneurial intention, respectively $(\beta=0,428$, $\mathrm{p}<0,001 ; \beta=0,317, \mathrm{p}<0,001)$. The hypotheses 3 and 4 are validated.

In order to test the research hypotheses, that are the potential moderating effect of propensity to act between (perceived desirability, perceived feasibility) and entrepreneurial intention, we should calculate the products of the two variables (independent variable * moderating variable). The moderating role is set if the coefficient of multiplicative effect is statistically significant (Aiken \& West, 1991).The results of the regression reveal thatthe propensity to act has a moderating effect between the perceived desirability and entrepreneurial intention $(\beta=0$, 107, $\mathrm{p}<0.01$ ), what confirms the hypothesis H5. On the other hand, we did not find a moderating effect of the propensity to act between the perceived feasibility and the entrepreneurial intention $(\beta=-0,042, p>0.05)$. The hypothesis H6 is thus invalidated.

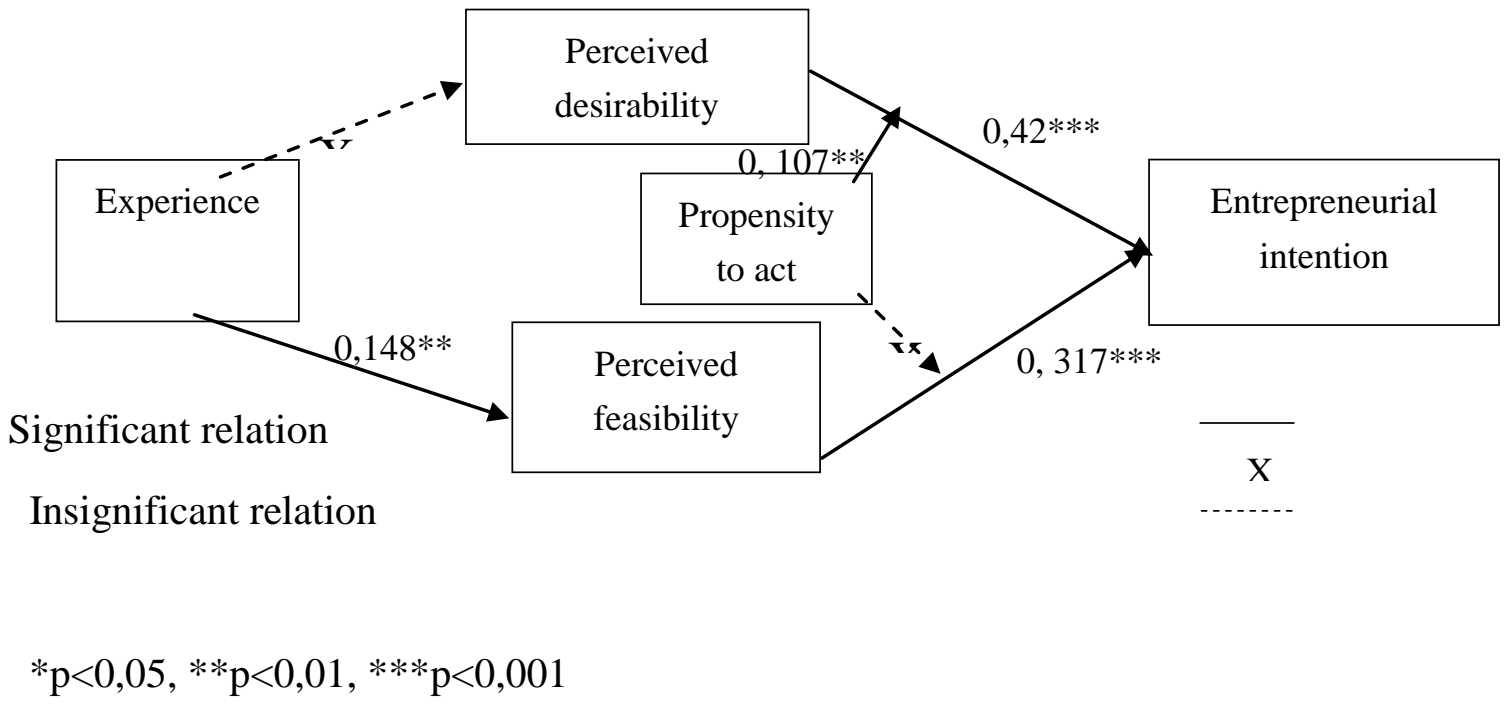

Figure 3. Results of full model 


\section{Discussion and Conclusion}

The results of the statistical analyses allowed to validate globally our model of research. Indeed, the experience seems at first has no effect on the perceived desirability (H1), in other words, the attraction towards the entrepreneurship does not seem to have a relation with the years of experience. This result confirms the results of Yatribi \& Balhadj (2016b)who find that the entrepreneurial intention among the employees is more guided by the attraction at the young employees than the older employees. Then, we validated the hypothesis 2 which stipulates that the experience has a positive influence on perception of feasibility. This result is completely natural coach with the accumulation of the years of experience, the individual accumulates a know-how, a savings, and professionals' network. Yatribi \& Balhadj (2016a)underline that the experience accumulated during the career allows in employee to have an entrepreneurial self-efficacy.

Our study shows that the used model of intention can be useful to predict the intentions to create a company at the employees. Indeed, about $31 \%$ of the variance of the intention is explained by this one. However, this rate remains nevertheless below those found in other quantitative studies on the entrepreneurial intention. This difference can be explained by the studied population. Indeed, in our case, we tried to explain the entrepreneurial intention at the employees, this one would be probably bound to other factors bound to the work. For example, the variable of the job satisfaction was identified by certain authors as being a major history in the entrepreneurial intention (Lee, Wong, Foo \& Leung, 2011). On their part, Yatribi \& Balhadj (2016a)found that the low job satisfaction as a component of the entrepreneurial motivation among the executives-engineers. Other authors found a link between the organizational commitment and the entrepreneurial intention(Kickul \& Zaper, 2000). Schein (2004)indicate that the organizational culture has an effect on the way the collaborators think and make decisions, as that to begin. The influence of the job satisfaction on the entrepreneurial intention is more relevant still when the employees are in search of a more challenging job where they can develop and value their know-how and their skills (Couger, 1988).

As regards the moderating effect of the propensity in the action, our results reveal a moderating effect between the perception of desirability and the entrepreneurial intention. Krueger (1993), in the United States, have tested this effect on the intentions to become an entrepreneur of 126 young graduates making at present in the face of a choice of career. His results end in a moderating effect of the propensity. On the other hand, our psychological measure of the propensity in the action showed itself ineffective to moderate the effect of the perception of feasibility on the entrepreneurial intention.

\subsection{Implications for research}

First of all, it should be noted that our research is among the rare works on entrepreneurial intention that were made on employees. In Morocco, and to our knowledge, there is no research on the topic.

Our results reveal that the model ofKrueger (1993)is not rather adequate to explain the 
entrepreneurial intention at the employees. Other theoretical approaches are necessary to complete this model. WhileKrueger (1993)put in perspective the importance of the effect of the "propensity to act", this one seems important in our case. Indeed, the fact that we found a moderating effect of the propensity to act between the perceived desirability and the entrepreneurial intention means that the entrepreneurial intention at the employees must be otherwise approached. Indeed, the propensity to act is considered as personality's variable, it means that the employees with a strong propensity to act have more intention to create a company. For example, the theory of adjustment Person-environment can be very useful for better explained the entrepreneurial intention specifically among. According to this theory, there are types of personality more or less sensitive) to certain organizational factors. They are generally attracted by the work which suits to their personality, their interests and their values (Wright \& Grant, 2010). The inadequacy between the personality of the individual and the working environment can bring to a situation of dissatisfaction in the work then in the entrepreneurial intention. It should be noted that all the theoretical frames on the entrepreneurial intention does not integrate in a clarify way the working environment of the individual because these models were conceived in the majority of the cases on a population of students. It is risked to say that these models are also adequate to explain the entrepreneurial intention among the employees. The variance been understandable by $31 \%$ which we found supports our words. Other variables bound to the working environment should be considered in the explanation of the intention.

\subsection{Implications for practice}

Our results suggest that it's important for the human resources department to know which are the types of personality the most attracted by the new business start-up, for which reasons they make it while some less intend to create a company that others. Our study showed that employees with a personality marked by a strong "propensity to act" are more attracted to the entrepreneurship. Finally, we showed that the experience has an effect on the perceived feasibility, it means, that for public authorities, he could be useful to promote the entrepreneurial culture at the oldest employees, to maintain them in service. Their know-how and their experience can be a real opportunity to be used to create more company and employment.

\subsection{Study limitations}

If this study brings a meaningful contribution to the understanding the developmental mechanisms of the entrepreneurial behaviour among engineers, it has limitations. We identified some usual limits with a quantitative work of hypothético-deductive. On one hand, the punctual nature, which is in cross section with the data collection, limits the generalizability of the results. On the other hand, the collected data are based on intention and self-perception declarations, and not on the observation of actual behaviours, which might lead to a bias of social desirability (Amabile, Hil, Hennessey \& Tighe, 1995). Finally, this bias is clear when the same questionnaire measures the dependent and independent variables. We have tries to restrict the impact of this limit by guarantying the respondents' anonymity, by using strong measuring scales, then by organizing the items' order so that the dependent 
and independent variables can easily be distinguished (Podsakoff, MacKenzie, Lee \& Podsakoff, 2003).

\subsection{Perspectives for the future researches}

In this study, we limited ourselves to the prediction of the intention to create a company and didn't include the prediction of the real behavior. Gold, the main interest of the models of intention rests on their predictive capacity of the behavior. It would be interesting to proceed to a longitudinal study to allow us to know so actually the engineers having declared to intend to create a company really passed in the entrepreneurial act.

The future researches could take considering other theories to explain better the entrepreneurial intention among the employees. We recommend strongly the theory of adjustment Person-environment to integrate at the same time factors bound to the individual (for example, the need of achievement, the need of autonomy) and those bound to the work environment (for example, management style, organizational justice, autonomy in the work), and how these factors interact to explain the entrepreneurial intention at the employees. Finally, Davidsson and Wiklund(2001) suggest that the study of the entrepreneurial intention in an organizational context requires multilevel data, what the literature has difficulty in offering to this day.

\section{References}

Aiken, L. S. \& West, S. G. (1991). Multiple regression: Testing and interpreting interactions. Thousand Oaks, CA, US: Sage Publications, Inc, 1991.

Ajzen, I. (1991). The theory of planned behavior. Theories of Cognitive Self-Regulation, 50 (2), s. 179-211.

Ajzen, I. \& Fishbein, M. (1970). The prediction of behavior from attitudinal and normative variables. Journal of Experimental Social Psychology, 6 (4), s. 466-487.

Amabile, T. M., Hil, K. G., Hennessey, B. A. \& Tighe, E. M. (1995). The Work Preference Inventory: Assessing intrinsic and extrinsic motivational orientations: Correction. Journal of Personality and Social Psychology, 68 (4), s. 580-580.

Bagozzi, R. P. \& Yi, Y. (1991). Multitrait-Multimethod Matrices in Consumer Research. Journal of Consumer Research, (4), s. 426.

Bird, B. (1988). Implementing Entrepreneurial Ideas: The Case for Intention. The Academy of Management Review, (3), s. 442.

Boyd, N. G. \& Vozikis, G. S. (1994). The Influence of Self-Efficacy on the Development of Entrepreneurial Intentions and Actions. Entrepreneurship: Theory \& Practice, 18 (4), s. 63.

Boyer, R. \& Michel, D. (1998). Innovation et croissance. La Documentation française. Paris.

Couger, J. D. (1988). Motivators versus demotivators in the IS environment. Journal of 
Systems Management, 39 (6), s. 36-41.

Davidsson, P. (1995). Culture, structure and regional levels of entrepreneurship. Entrepreneurship \& Regional Development, 7 (1), s. 41.

Davidsson, P. \& Wiklund, J. (2001). Levels of analysis in entrepreneurship research: Current research practice and suggestions for the future. Entrepreneurshiptheory and Practice, 25 (4), s. $81-100$.

Fayolle, A. (2001). D'une approche typologique de l'entrepreneuriat chez les ingénieurs à la reconstruction d'itinéraires d'ingénieurs entrepreneurs. Revue de l'Entrepreneuriat, Vol. 1 (1), s. 77-97.

Fornell, C. \&Larcker, D. F. (1981). Evaluating Structural Equation Models with Unobservable Variables and Measurement Error. Journal of Marketing Research (JMR), 18 (1), s. 39.

Gaudin, T. (1984). Les ingénieurs et l'innovation. Culture technique, (12), s. 133-136.

Kickul, J. \& Zaper, J. A. (2000). Untying the Knot: Do Personal and Organizational Determinants Influence Entrepreneurial intentions? Journal of Small Business and Entrepreneurship, 15 (3), s. 57-77.

Kolvereid, L. (1996). Prediction of employment status choice intentions. Entrepreneurship: Theory \& Practice, 21 (1), s. 47.

Krueger, N. (1993). The Impact of Prior Entrepreneurial Exposure on Perceptions of New Venture Feasibility and Desirability. Entrepreneurship: Theory \& Practice, 18 (1), s. 5.

Krueger, N. F. \& Brazeal, D. V. (1994). Entrepreneurial Potential and Potential Entrepreneurs. Entrepreneurship: Theory \& Practice, 18 (3), s. 91.

Krueger, N. F. \& Carsrud, A. L. (1993). Entrepreneurial intentions: Applying the theory of planned behaviour. Entrepreneurship \& Regional Development, 5 (4), s. 315.

Krueger, N. F. \& Kickul, J. (2011). Cognitive style and the specification of entrepreneurial intentions models. NeuroPsychoEconomics Conference Proceedings, s. 22-22.

Krueger, N. F., Reilly, M. D. \& Carsrud, A. L. (2000). Competing models of entrepreneurial intentions. Journal of Business Venturing, 15 (5-6), s. 411-432.

Lavoie, M. \& Finnie, R. (1998). The early careers of engineers and the accumulation of skills in the Canadian economy. Economics of Innovation and New Technology, 7 (1), s. 53-59.

Learned, K. E. (1992). What Happened Before the Organization? A Model of Organization Formation. Entrepreneurship: Theory \& Practice, 17 (1), s. 39-48.

Lee, L., Wong, P. K., Foo, M. D. \& Leung, A. (2011). Entrepreneurial intentions: The influence of organizational and individual factors. Journal of Business Venturing, 26 (1), s. 124-136. 


\section{Macrothink}

International Journal of Human Resource Studies

ISSN 2162-3058 2016, Vol. 6, No. 2

Podsakoff, P. M., MacKenzie, S. B., Lee, J. Y. \& Podsakoff, N. P. (2003). Common method biases in behavioral research: a critical review of the literature and recommended remedies. Journal of Applied Psychology, 88 (5), s. 879-903.

Schein, E. H. (2004). Organizational culture and leadership (3. udg.). San Francisco: Jossey-Bass Inc Pub.

Schlaegel, C. \& Koenig, M. (2014). Determinants of Entrepreneurial Intent: A Meta-Analytic Test and Integration of Competing Models. Entrepreneurship: Theory \& Practice, 38 (2), s. 291.

Shapero, A. \& Sokol, L. (1982). The social dimensions of entrepreneurship. In: Kent, C.A., Sexton, D.L., Vesper, K.H. (Eds.), Encyclopedia of Entrepreneurship. Prentice Hall, Englewood Cliffs, NJ, s. 72-90.

Simosi, M., Rousseau, D. M. \& Daskalaki, M. (2015). When career paths cease to exist: A qualitative study of career behavior in a crisis economy. Journal of VocationalBehavior, 91, s. 134-146.

Thietart, R.-A. (2014). Méthodes de recherche en management (4ème udg.). Dunod.

Thompson, E. R. (2009). Individual entrepreneurial intent: Construct clarification and development of an internationally reliable metric. Entrepreneurship Theory and Practice, 33 (3), s. 669-694.

Wright, B. E. \& Grant, A. M. (2010). Unanswered Questions about Public Service Motivation: Designing Research to Address Key Issues of Emergence and Effects. Public Administration Review, 70 (5), s. 691-700.

Yatribi, T. \&Balhadj, S. (2016a). L'entrepreneuriat comme orientation de carrière : Le cas des ingénieurs marocains. International Journal of Innovation and Applied Studies, (In press).

Yatribi, T. \& Balhadj, S. (2016b). The influence of the age on the entrepreneurial intention: case of the Moroccan executives-engineers. Australian Journal of Business and Management Research, 3 (1).

\section{Copyright Disclaimer}

Copyright for this article is retained by the author(s), with first publication rights granted to the journal.

This is an open-access article distributed under the terms and conditions of the Creative Commons Attribution license (http://creativecommons.org/licenses/by/3.0/). 